\title{
TRADUUÇ̃̃O AUTOMÁTICA NO ENSINO E NA APRENDIZAGEM DE LÍNGUAS NÃO MATERNAS: PERCEPÇÕES, ATITUDES E OPINIÕES DE PROFESSORES
}

\author{
MACHINE TRANSLATION IN NON-NATIVE LANGUAGE TEACHING AND LEARNING: \\ TEACHERS' PERCEPTIONS, ATTITUDES, AND OPINIONS
}

\author{
Gbènoukpo Gérard Nouatin * \\ Vicente Aguimar Parreiras*
}

\begin{abstract}
RESUMO
O uso da Tradução Automática (TA) por aprendizes de línguas não maternas é uma realidade apontada por pesquisas (NOUATIN, 2018; ALHAISONI e ALHASYSONY, 2017; CLIFFORD et al., 2013). Tal prática suscita reações por parte de docentes, principalmente por preocupação com o processo de aprendizagem de línguas dos alunos que recorrem ao recurso e com a possibilidade de fraude por parte de discentes que podem, por exemplo, entregar aos seus professores traduções automáticas como produções próprias (NOUATIN, 2018; CLIFFORD et al., 2013; SOMERS et al., 2006). Assim, estudiosos como Henshaw (2020) e Ducar; Schocket (2018) realizaram pesquisas visando encontrar a melhor forma de lidar com a prática de uso da TA no ensino e na aprendizagem de línguas não maternas. Foi buscando contribuir para essa discussão, trazendo percepções, atitudes e opiniões de professores de um contexto de ensino e de aprendizagem de línguas brasileiro, que a pesquisa que originou este artigo foi realizada. Os dados, gerados aplicando um questionário online (Google forms) a 12 professores de línguas, foram tabulados, categorizados e interpretados. Os resultados indicam que as percepções dos participantes da nossa pesquisa convergem com as dos participantes de pesquisas de outros contextos que abordaram esse aspecto do assunto. Também descobrimos que esses professores têm atitudes flexíveis e opiniões favoráveis em relação ao uso da TA por aprendizes de línguas não maternas e até mesmo à integração da TA ao ensino e à aprendizagem de línguas, desde que haja condições adequadas.

Palavras-chave: aprendizagem de línguas; ensino de línguas; tradução automática.
\end{abstract}

\section{ABSTRACT}

The use of Machine Translation (MT) by non-native language learners is a reality highlighted by studies (NOUATIN, 2018; ALHAISONI and ALHASYSONY, 2017; CLIFFORD et al., 2013). Such practice provokes reactions on the part of teachers, mainly due to their concern with the language learning process of students who use MT and with the possibility of cheating, on the part of students, who may hand in to their teachers, machine translations as their own productions (NOUATIN, 2018; CLIFFORD et al., 2013; SOMERS et al., 2006). Hence, researches (HENSHAW, 2020; DUCAR e SCHOCKET, 2018) are being carried out, to find out the best way to cope with the practice of using MT in non-native language teaching and learning. The study that grounded this article has been conducted to contribute to that discussion bringing to the table the perceptions, attitudes, and opinions of teachers from a Brazilian language teaching and learning context. The data, generated applying an online questionnaire (Google forms) to 12 language teachers, have been tabulated, categorized and interpreted. The results show that the language instructors questioned have perceptions similar to those of the participants of researches conducted in other contexts that discussed that aspect of the question. We also found out that those teachers have flexible attitudes and favourable opinions towards the use of MT by non-native language learners and even towards the integration of MT to language teaching and learning since there are adequate conditions.

Keywords: machine translation; language learning; language teaching.

\section{INTRODUÇÃO}

Neste artigo, focalizamos percepções, atitudes e opiniões de professores quanto ao uso da Tradução Automática (TA) no ensino e na aprendizagem de línguas não maternas. Distinguem-se atualmente quatro modalidades de tradução nesses processos: i) "tradução pedagógica" (LAVAULT, 1985, apud SÁNCHEZ IGLESIAS, 2009)1, que é a atividade de tradução "utilizada em sala de aula como ferramenta pedagógica para reforçar e verificar a aprendizagem utilizando textos, análise contrastiva e reflexão" (HURTADO ALBIR, 1998, apud BRANCO, 2009, p. 186); ii) "tradução interiorizada" (HURTADO ALBIR, 1987, apud ARRIBA GARCÍA, 1996), que é "um mecanismo espontâneo e automático que se dá, sobretudo, no início da aprendizagem e [que] o aluno usa para contrastar a língua

\footnotetext{
* Centro Federal de Educação Tecnológica de Minas Gerais (CEFET-MG), Belo Horizonte, MG. Brasil. nouatingerardo@yahoo.fr Orcid: https://orcid.org/0000-0003-0582-7966

** Centro Federal de Educação Tecnológica de Minas Gerais (CEFET-MG), Belo Horizonte, MG. Brasil. vicenteparreiras@gmail.com Orcid: https://orcid.org/0000-0001-6002-7967

1. De acordo com Sánchez Iglesias (2009), o termo se difundiu a partir do trabalho de Elisabeth Lavault (1985).
} 
estrangeira com a própria"2 (HURTADO ALBIR, 1988b, apud ASQUERINO EGOSCOZÁBAL, 2015, p. 5); iii) "tradução explicativa" (HURTADO ALBIR, 1987, apud ARRIBA GARCÍA, 1996), que "consiste em empregar, num momento pontual, a tradução para explicar de forma mais fácil ao aluno o significado de palavras monossêmicas ou que é difícil explicar sem recorrer à língua materna do aluno"33 (HURTADO ALBIR, 1988b, apud ASQUERINO EGOSCOZÁBAL, 2015); e, por último, iv) o recurso à tradução automática por aprendizes de línguas não maternas para fins de aprendizagem e de comunicação (CLIFFORD et al., 2013; ALHAISONI e ALHASYSONY, 2017; NOUATIN, 2018), ao qual nos referiremos doravante como "Tradução Automática Didatizada" (TAD), termo que está sendo cunhado por Nouatin neste artigo.

Pesquisas (CLIFFORD et al., 2013; ALHAISONI e ALHASYSONY, 2017; NOUATIN, 2018) comprovam que aprendizes de línguas não maternas recorrem à TA para fins de aprendizagem e de comunicação. $\mathrm{O}$ uso da ferramenta por professores para ensinar línguas é igualmente um fato como demonstram dados do estudo de Niño (2009) e também deste trabalho, como veremos posteriormente, além de existirem pesquisas (CLIFFORD et al., 2013; NOUATIN, 2018; NIÑO, 2009) que incentivam isso. Então, a denominação "Tradução Automática Didatizada" (TAD) tem a pretensão de abarcar a utilização da TA tanto na aprendizagem quanto no ensino de línguas e o verbo "didatizar", cujo particípio "didatizada" é empregado, possui essa ambivalência de o aluno e o professor transformando a TA em um recurso didático; o primeiro usando a ferramenta para aprender línguas e o segundo para ensinar línguas. No entanto, existem professores céticos em relação à utilidade e a um impacto positivo da TA na aprendizagem de línguas e preocupados com a potencial desonestidade acadêmica ou intelectual por parte dos alunos envolvendo o recurso (SOMERS et al., 2006; CLIFFORD et al., 2013). Contudo, há divergências de opinião em torno dessas questões, tanto entre alunos e professores (CLIFFORD et al., 2013; NOUATIN, 2018) quanto de professores entre si (HENSHAW, 2020).

Tais divergências suscitaram a pesquisa que gerou este artigo e que foi planejada com o propósito de contribuir para as discussões acadêmicas sobre o uso da TA no ensino e na aprendizagem de línguas não maternas, trazendo percepções, atitudes e opiniões de professores de um contexto de ensino e de aprendizagem brasileiro, que apresentaremos posteriormente neste trabalho. Antes de apresentarmos e discutirmos os resultados do estudo e de encerrarmos este texto com considerações finais, apresentamos estudos sobre a TA no ensino e na aprendizagem de línguas não maternas, assim como o caminho metodológico percorrido.

\section{ESTUDOS SOBRE A TA NO ENSINO E NA APRENDIZAGEM DE LÍNGUAS NÃO MATERNAS}

Alunos que cursam disciplinas de línguas não maternas como parte da grade curricular, os que frequentam cursos de idioma e aqueles que fazem cursos superiores de filologias, literaturas e civilizações estrangeiras, entre outros usuários, recorrem à TA. Tal prática preocupa professores, que temem que a TA comprometa o processo de aprendizagem dos alunos devido às suas incorreções lexicogramaticais e às suas limitações do ponto de vista discursivo e intercultural, ou mesmo por medo de que os discentes desenvolvam dependência à TA (CLIFFORD et al. 2013; NOUATIN, 2018). A possibilidade de os alunos perderem a motivação para aprender ou mesmo para se tornarem professores de línguas não maternas em decorrência da disponibilidade e livre acesso a uma TA de boa qualidade é outra preocupação (DUCAR e SCHOCKET, 2018). De acordo com Somers et al. (2006) e Clifford et al. (2013), também inquieta a professores a questão da fraude (cheating, plagiarism) envolvendo a TA. Com efeito, alunos assumem a total autoria de traduções automáticas (CLIFFORD et al. 2013; SOMERS et al., 2006; MCCARTHY, 2004), por exemplo, entregando a seus professores tarefas de produção escrita originalmente feitas em língua materna e depois traduzidas para a língua não materna que estudam, por meio de tradutores automáticos.

Com relação à qualidade do seu desempenho, Ducar e Schocket (2018) sustentam que os tradutores automáticos estão cada dia melhores, superando muitos dos seus defeitos (tradução de nomes próprios; produção escrita não natural devido ao emprego de vocabulário literário, inabitual ou arcaico; tradução literal e problemas com palavras polissêmicas; não tradução de palavras mal escritas, dificuldades com expressões idiomáticas menos

2. Nossa tradução para: "un mecanismo espontáneo y automático que se produce, sobre todo, al principio del aprendizaje y lo emplea el alumno para contrastar la lengua extranjera con la propia" (HURTADO ALBIR, 1988b, apud ASQUERINO EGOSCOZÁBAL, 2015, p. 5).

3. Nossa tradução para: "consiste en emplear, en un momento concreto, la traducción para explicar de forma más fácil al alumno el significado de palabras monosémicas o que resultan difíciles de explicar si no se recurre a la lengua materna del alumno." (HURTADO ALBIR, 1988b, apud ASQUERINO EGOSCOZÁBAL, 2015). 
comuns, problemas com conectores discursivos e correferência) evidenciados por Enkin e Mejías-Bikandi (2016), Groves e Mundt (2015), Correa (2014), Niño (2009), Somers et al. (2006), Williams (2006), a ponto de poder ser irreconhecível tratar-se de TA (STAPLETON e KIN, 2019). No entanto, como afirmam Ducar e Schocket (2018), há defeitos da TA apontados por esses mesmos pesquisadores e os próprios Ducar e Schocket (2018), a saber: problemas de gramática, de pragmática, de registro (variantes formal e informal) e com referências culturais, que persistem. Porém, os alunos sempre tiveram certa consciência das imperfeições e limitações dos sistemas de TA e, por isso, resolveram remediá-las empregando estratégias desenvolvidas por eles mesmos ao longo dos anos de uso (CLIFFORD et al. 2013; NOUATIN, 2018), pois a consideram útil como ferramenta de aprendizagem e de comunicação apesar dos defeitos desse tipo de programa computacional.

No que diz respeito ao risco de os alunos desenvolverem dependência da TA, dados da pesquisa de Nouatin (2018) provam que não há o que temer.

Ainda sobre o uso da TA por aprendizes de línguas, Lee (2019) fez um levantamento de pesquisas que demonstram que o recurso digital beneficia a aprendizagem de línguas dos pontos de vista cognitivo, linguístico e afetivo. Como explica a pesquisadora (2019, p. 2),

[d] o ponto de vista cognitivo, a TA reduz a carga cognitiva dos alunos fazendo traduções preliminares (Baraniello et al., 2016; Lewis, 1997), além de promover aprendizagem autônoma (Godwin-Jones, 2015; Wong e Lee, 2016). Do ponto de vista linguístico, a TA ajuda os alunos na aquisição de conhecimento léxico-gramatical (Bahri e Mahadi, 2016; Doherty e Kenny, 2014; Wong e Lee, 2016), assim como os auxilia na leitura e escrita de texto (Alhaisoni e Alhaysony, 2017; Garcia e Pena, 2011; Kumar, 2012), e, por fim, promove a aprendizagem de línguas (Belam, 2003; Niño, 2009; Shei, 2002a; Wong e Lee, 2016). Williams (2006) apontou que o uso da TA pode "forçar os alunos a pensar sobre a linguagem como uma ferramenta de comunicação e não como um conjunto de palavras ou frases fora de contexto" (p. 574). Do ponto de vista afetivo, diminui a ansiedade linguística dos alunos (Bahri e Mahadi, 2016; Jin, 2013), aumenta sua motivação e a confiança (Kliffer, 2008; Niño, 2008) e cria um ambiente de aprendizagem não ameaçador (Niño, 2009) ${ }^{4}$.

No que diz respeito aos professores, Henshaw (2020) constatou que eles têm posturas divergentes, que a estudiosa organiza em cinco abordagens: (a) "Não é confiável" ("Can't trust this" approach); (b) "Só palavras isoladas" ("One word only" approach); (c) "Tolerância zero" ("Zero tolerance" approach); (d) "Onde você aprendeu isso?" ("Where did you learn that?" approach); e (e) "Se você não pode vencer seu inimigo, una-se a ele" ("If you can't beat them, join them" approach). Tendo observado certas limitações nessas abordagens, às vezes problemas sérios do ponto de vista pedagógico, Henshaw (2020) propõe uma abordagem própria, voltada para a redução da motivação dos alunos para usar TA operando mudanças pedagógicas e práticas nos cursos de idioma, que, de acordo com a autora, poderia ser chamada de abordagem do "Quem perde são eles" ("it's their loss" approach). Com relação às considerações pedagógicas, a autora $(2020, \mathrm{~s} / \mathrm{p})$ enumerou cinco perguntas norteadoras das práticas de ensino, a saber:

1. Os alunos com o nível de proficiência para o qual a tarefa foi pensada são capazes de fazê-la? [...]

2. Os alunos estão sendo avaliados conforme o que podem fazer com a língua no nível de proficiência em que estão? [...]

3. Os nossos alunos foram bem preparados para fazerem tarefas relativamente sem assistência? [...]

4. Será que estamos indo muito depressa da recepção à produção de texto por parte dos alunos? [...]

5. As nossas metas são realistas? $[\ldots]^{5}$

A respeito das considerações práticas, Henshaw (2020) recomenda que professores classifiquem as tarefas que elaboram nas três categorias seguintes: verde (os alunos vão provavelmente sucumbir à tentação de recorrer à TA para fazer a tarefa), amarela (os alunos podem buscar ajuda da TA, mas o formato da tarefa torna-a menos útil) e vermelha (o uso da TA não seria nada prático ou mesmo impossível para a realização da tarefa). A autora ainda sugere

4. Nossa tradução para: "From the cognitive perspective, it reduces cognitive load by doing preliminary translations (Baraniello et al., 2016; Lewis, 1997) and promotes self-directed learning (Godwin-Jones, 2015; Wong \& Lee, 2016). From the linguistic perspective, MT supports lexico-grammatical knowledge (Bahri \& Mahadi, 2016; Doherty \& Kenny, 2014; Wong \& Lee, 2016), promotes reading comprehension and writing (Alhaisoni \& Alhaysony, 2017; Garcia \& Pena, 2011; Kumar, 2012), and ultimately fosters language learning (Belam, 2003; Niño, 2009; Shei, 2002a; Wong \& Lee, 2016). Williams (2006) pointed out that the use of MT can "force students to think about language as a communication tool, not as a set of decontextualized vocabulary words or phrases" (p. 574). From the affective perspective, it lowers language anxiety (Bahri \& Mahadi, 2016; Jin, 2013), increases motivation and confidence (Kliffer, 2008; Niño, 2008), and creates a nonthreatening learning environment $(\mathrm{Niño}, 2009)$. At the same time, studies also report the drawbacks of MT, such as erroneous sentences, incorrect lexis, and inaccurate grammar (Bahri \& Mahadi, 2016; Josefsson, 2011; Niño, 2008, 2009)." (LEE, 2019, p. 2)

5. Nossa tradução para:

"1. Are students at the targeted proficiency level able to do what we're asking them to do? [...]

2. Are students being evaluated on what they can do with the language at the targeted level? [...]

3. Have we adequately prepared students to do the assignment in a relatively unassisted way? [...]

4. Are we moving too quickly from input to output? [...]

5. Are we being realistic with respect to what we are aiming for? [...]" (HENSHAW, 2020, s/p) 
que, feito isso, os docentes atribuam maiores porcentagens da nota total às tarefas da categoria vermelha seguidas das da amarela e por fim das da verde.

As abordagens de Henshaw (2020) dizem respeito tanto à reação e atitudes dos professores diante do uso da TA por seus alunos (as abordagens do "Não é confiável", "Só palavras isoladas", "Tolerância zero", "Onde você aprendeu isso?", "Quem perde são eles"), quanto a seu uso pelo professor para ensinar (a abordagem do "Se você não pode vencer seu inimigo, una-se a ele"). Quanto a esse último ponto, Niño (2009) afirma que Anderson (1995) e Richmond (1994) fizeram um "uso da TA como modelo ruim" (use of MT as a bad model), utilizando as falhas da TA para trabalhar as diferenças da primeira língua para a língua alvo do aluno a fim de reforçar nele a consciência contrastiva entre as duas línguas. Ainda de acordo com Niño (2009), esse tipo de uso também é recomendado por estudiosos como Somers (2003) e Ball (1989), sendo esse último o primeiro autor a questionar o papel da TA na didática de línguas. A temática é investigada de outros ângulos também.

Pesquisas de natureza exploratória, como as de Conde Noguerol (2018), Nouatin (2018), Alhaisoni; Alhaysony, (2017), Clifford et al., (2013), geralmente buscam comprovar a utilização da TA por aprendizes de línguas não maternas, além de se interessarem pelos motivos, frequência e finalidades desse uso, assim como pela maneira como tal recurso é usado. Também existem estudos que avaliam o desempenho de um ou mais tradutores automáticos ou destacam pontos fortes e fracos da TA com base em resultados de testes ou em opiniões dos próprios alunos, tais como os de Putri e Havid (2015), Stapleton e Kin (2019), Ducar e Schocket (2018), embora todos os trabalhos acabem abordando esse aspecto de uma forma ou de outra.

As impressões, percepções e atitudes de alunos e professores sobre a tradução automática didatizada por aprendizes de línguas não maternas também são questões abordadas por estudos de autores tais como: Clifford et al. (2013), Alhaisoni e Alhaysony (2017), Nouatin (2018), Lee (2019) e Henshaw (2020). Inferimos dessas pesquisas que não há consenso entre professores sobre a utilização da TA para o ensino. Também não há consenso entre professores, nem entre professores e alunos, quanto aos impactos do uso da ferramenta digital na aprendizagem de línguas nem em relação a que modos de usá-la poderiam se configurar como fraude acadêmica ou intelectual por parte dos alunos. Com relação a essa última questão, Nouatin (2018), Alhaisoni e Alhaysony (2017) e Clifford et al. (2013) avaliam que se fazem necessários diálogos entre todas as partes envolvidas no ensino e na aprendizagem de línguas para se definir o que é fraude (cheating, plagiarism) no uso de tradutores automáticos e deixar isso claro nas ementas de disciplina, planos de ensino e regulamentos de curso.

É para essas discussões que este trabalho pretende contribuir. Nesse sentido, realizamos uma pesquisa de cunho exploratório procedendo da maneira que descrevemos na seção a seguir.

\section{METODOLOGIA}

Nesta seção traçamos o percurso metodológico da pesquisa apresentando nossos participantes, os instrumentos e os procedimentos de coleta dos dados, bem como as técnicas de análise que adotamos.

\subsection{Perfis dos participantes}

Os participantes da pesquisa são 12 (doze) professores de inglês e ou de espanhol como línguas não maternas atuando no ensino médio no Centro Federal de Educação Tecnológica de Minas Gerais (CEFET-MG). Trata-se de 01 (uma) pós-doutoranda, 01 (um) doutorando, 04 (quatro) doutores e 06 (seis) mestres, de 32 a 55 anos de idade e com entre 10 e 32 anos de experiência no ensino. Para garantir o sigilo da identidade dos participantes, eles receberam codinomes compostos pela letra $\mathrm{P}$, remetendo a professor(a), seguida do número sequencial das respostas ao questionário. Dessa maneira, são designados como P1, P2, e assim sucessivamente até P12.

\subsection{Instrumento e procedimento de geração de dados}

Para coletar os dados da pesquisa, foi elaborado um questionário (um formulário do Google) inspirado nos de Nouatin (2018), de Alhaisoni e Alhaysony (2017), Clifford et al. (2013) e de Niño (2009). O questionário, cujas perguntas foram elaboradas a partir do objetivo do estudo, foi enviado aos participantes via o aplicativo de mensagens 
WhatsApp, por meio do qual também foram recebidos comentários que alguns participantes enviaram por livre e espontânea vontade, para completar suas respostas.

\subsection{Procedimentos de análise dos dados}

Após separação das respostas que dizem respeito aos perfis dos participantes, as demais respostas foram organizadas em quatro categorias que delineiam a estrutura da próxima seção em que apresentamos os resultados, a saber: (1) a relação dos professores questionados com a TA, (2) a ciência ou não desses docentes da prática do uso de TA por seus alunos, (3) as atitudes e opiniões dos participantes a respeito dessa prática e (4) o posicionamento desses professores em relação à integração da TA ao ensino e à aprendizagem de línguas não maternas. Após essa etapa, os resultados foram discutidos fazendo dialogar dados e resultados da nossa pesquisa com os de outros estudos com focos similares.

\section{RESULTADOS}

Iniciamos a presente pesquisa buscando estabelecer a relação dos professores participantes com a TA. Para tal, perguntamos aos participantes, em primeiro lugar, com que frequência eles usam TA para fins pessoais. 06 (seis) deles afirmaram que usam o recurso às vezes, 03 (três) raramente, 02 (dois) frequentemente e 01 (um) muito frequentemente. Em seguida, perguntamos a eles com que frequência integram a TA às suas práticas docentes, ao que 05 (cinco) responderam às vezes, 03 (três) raramente, 02 (dois) nunca, 01 (um) frequentemente e outro (01) muito frequentemente. Ao indagarmos quais tradutor(es) automático(s) os participantes usam, sem discriminação de usos para fins pessoais e em suas práticas docentes, descobrimos que todos os respondentes usam apenas Google Tradutor.

Em seguida, procuramos saber se os participantes têm consciência de que seus alunos recorrem à TA para fins comunicativos ou para aprender línguas, como foi comprovado na pesquisa de Nouatin (2018) e em pesquisas prévias. 10 (dez) dos professores afirmaram ter ciência disso, enquanto 02 (dois) disseram imaginar que sim. Outros dados pertinentes que nós, professores, devemos saber são os que Nouatin (2018) agrupou dentro da subseção "Relação dos sujeitos com a TA" do capítulo de apresentação e discussão dos resultados: desde quando os questionados vêm recorrendo à $\mathrm{TA}_{\text {; }}$ como a conheceram; os motivos de preferência ou fidelidade a um ou mais tradutores automáticos; frequência de recurso à TA por tarefa e em geral; variação na frequência de uso de TA ao longo do tempo; os motivos pelos quais os alunos participantes recorrem à $\mathrm{TA}_{;}$a finalidade de uso; as situações de uso para traduzir da sua língua materna para a língua que estão aprendendo e vice-versa; as formas em que o tradutor automático ajuda na aprendizagem da língua alvo; a evidência de uso com senso crítico da TA por parte dos alunos a ponto de desenvolverem estratégias para melhorar a tradução automática e quais são essas estratégias.

Pesquisas (CLIFFORD et. al., 2013; NOUATIN, 2018; HENSHAW, 2020) apontam que professores proíbem ou dissuadem seus alunos de recorrerem à TA por receio de o uso do recurso por eles atrapalhar seus processos de aprendizagem de língua, devido à insegurança desses docentes em relação à qualidade do desempenho dos tradutores automáticos livres, além do seu medo de que os discentes desenvolvam dependência da ferramenta. Ainda de acordo com esses estudos, educadores também interditam a utilização da TA por seus educandos por motivos relacionados à questão da honestidade acadêmica ou intelectual, como apontamos anteriormente neste artigo.

Partindo desses dados, procuramos descobrir as opiniões desses professores participantes da nossa pesquisa diante do uso da TA por seus alunos. Abordamos o assunto começando com a questão da fraude em relação ao tamanho dos textos traduzidos automaticamente e às situações de uso. Então, em primeiro lugar, perguntamos aos participantes se consideram antiético, um pouco ético, ético ou totalmente ético que alunos usem tradutores automáticos para traduzir palavras isoladas, expressões isoladas, frases isoladas, parágrafos ou textos verbais maiores. A noção de ética em questão diz respeito ao princípio de honestidade intelectual ou acadêmica. Portanto, como nos estudos de Clifford et. al. (2013), de Alhaisoni e Alhaysony (2017) e de Nouatin (2018), trata-se de saber se, para os respondentes, a utilização da TA por alunos durante a realização de suas tarefas escolares constitui fraude (cheating, plagiarism), desonestidade intelectual ou acadêmica. Os dados obtidos são apresentados na tabela seguinte: 
Tabela 1. Honestidade intelectual e tamanho do texto

\begin{tabular}{|c|c|c|c|c|c|}
\cline { 2 - 6 } \multicolumn{1}{c|}{} & Palavras isoladas & $\begin{array}{c}\text { Expressões } \\
\text { isoladas }\end{array}$ & Frases isoladas & Parágrafos & $\begin{array}{c}\text { Textos verbais } \\
\text { maiores }\end{array}$ \\
\hline Antiético & 0 & 0 & 2 & 6 & 8 \\
\hline Um pouco ético & 0 & 0 & 4 & 4 & 2 \\
\hline Ético & 8 & 9 & 5 & 2 & 2 \\
\hline Totalmente ético & 4 & 3 & 1 & 0 & 0 \\
\hline
\end{tabular}

Fonte: questionário de pesquisa

Por meio desses dados, entendemos que quanto maior o segmento textual, menos ético os professores questionados consideram que os alunos usem tradutores automáticos para traduzi-lo ao fazerem suas tarefas escolares; demostrando, assim, ter a mesma opinião que os alunos questionados por Nouatin (2018) nesse quesito.

Em seguida, fizemos essa mesma pergunta, mas desta vez substituindo o tamanho do texto pela situação de recurso à TA. Apresentamos os dados na tabela a seguir:

Tabela 2. Honestidade intelectual e situação de uso

\begin{tabular}{|c|c|c|c|c|c|c|c|}
\cline { 2 - 8 } \multicolumn{1}{c|}{} & $\begin{array}{c}\text { Tarefas } \\
\text { de leitura } \\
\text { durante a } \\
\text { aula }\end{array}$ & $\begin{array}{c}\text { Tarefas } \\
\text { de escrita } \\
\text { durante a } \\
\text { aula }\end{array}$ & $\begin{array}{c}\text { Tarefas de } \\
\text { gramática } \\
\text { durante a } \\
\text { aula }\end{array}$ & $\begin{array}{c}\text { Tarefas de } \\
\text { leitura para } \\
\text { casa }\end{array}$ & $\begin{array}{c}\text { Tarefas de } \\
\text { escrita para } \\
\text { casa }\end{array}$ & $\begin{array}{c}\text { Tarefas de } \\
\text { gramática } \\
\text { para casa }\end{array}$ & $\begin{array}{c}\text { Tarefas de } \\
\text { tradução }\end{array}$ \\
\hline Antiético & 1 & 0 & 1 & 1 & 1 & 2 & 1 \\
\hline $\begin{array}{c}\text { Um pouco } \\
\text { ético }\end{array}$ & 7 & 5 & 6 & 6 & 6 & 5 & 5 \\
\hline Ético & 2 & 2 & 1 & 2 & 2 & 2 & 2 \\
\hline $\begin{array}{c}\text { Totalmente } \\
\text { ético }\end{array}$ & 2 & 5 & 4 & 3 & 3 & 3 & 4 \\
\hline
\end{tabular}

Fonte: questionário de pesquisa

Excetos os dados referentes aos professores que consideram totalmente ética a utilização da TA por alunos ao realizarem tarefas de escrita e de gramática em sala de aula, assim como durante tarefas de tradução, os números são bastante próximos de uma coluna para a outra, o que indica que, para os respondentes, o tipo de tarefa e o fato de o uso acontecer em aula ou em casa não fazem diferença, do mesmo modo que para os participantes de Nouatin (2018). Além disso, causa estranhamento ver que 05 (cinco), 04 (quatro) e outros 04 (quatro), de 12 (doze) docentes, pensam que é totalmente ético que discentes usem tradutores automáticos quando fazem atividades de escrita em aula, atividades de gramática em aula, bem como atividades de tradução, respectivamente. Com efeito, por se tratar de tarefas de produção de texto, entre as quais está a própria tradução, tais dados são surpreendes, já que

[a] relação entre TA e desonestidade acadêmica sempre foi a principal preocupação entre professores de línguas não maternas, os quais devem constantemente se perguntar o que seria fraude, tentar descobrir por que os alunos comentem fraude ou como evitar a desonestidade acadêmica por parte de aprendizes de línguas. ${ }^{6}$ (CLIFFORD et. al., 2013, p. 114)

Essa preocupação com fraude (cheating, plagiarism) por parte do aluno, envolvendo a TA, é perceptível tanto em trabalhos como os de Henshaw (2020), de Somers et al. (2006) e de McCarthy (2004), quanto nas respostas complementares dos respondentes P8 e P11. Com efeito, após terem respondido ao nosso questionário, quatro participantes nos enviaram, em formato de mensagem de voz e de mensagem escrita via o aplicativo de conversa WhatsApp, alguns comentários, que pediram ou autorizaram que considerássemos como adendos às suas respostas. Explicado isso, seguem os trechos de comentários em que percebemos a referida inquietação com fraude também nos dois participantes mencionados: "Se o tradutor for utilizado como ferramenta de suporte para o aprendiz, por mim, tudo bem. Se for usado como um "shortcut mequetrefe", sou radicalmente contra." (P8, mensagem escrita).

Eu acho que a questão de ser ético ou não aluno usar um tradutor automático, tudo depende, né, se o professor sabe ou não que ele estava usando. Se ele está usando isso para enganar por exemplo o professor. Um exemplo, o professor dá uma tarefa para casa, né, um

6. Nossa tradução para: "The relationship between MT and academic dishonesty has always been the primary concern among second or foreign language faculty, who must constantly question what constitutes cheating or try to find answers to why students cheat or how to avoid dishonesty among language learners." (CLIFFORD et. al., 2013, p. 114) 
pequeno texto. $\mathrm{O}$ aluno escreve o texto em português, joga o texto no tradutor e entrega pro professor como se fosse feito por ele. Isso seria antiético, sim. [...] Porque alguns nem leem. É simplesmente cópia e cola. Nem leem aquilo que o tradutor fez. Então, não dá para garantir, né? (P11, mensagem de voz)

Por outro lado, voltando aos dados apresentados na Tabela 2, a resposta mais recorrente foi "um pouco ético", seguida de "totalmente ético" e de "ético", sendo a resposta "antiético" a menos marcada com uma diferença muito grande em relação às duas primeiras. Considerando por um lado as respostas 'um pouco ético', 'ético' e 'totalmente ético' como forma de expressão de ausência de desonestidade intelectual pelos respondentes e, por outro, 'antiético' como o contrário, chegamos à conclusão de que esses professores não culpabilizam os alunos usuários da TA em nenhuma das situações de uso mencionadas no questionário.

No entanto, comentários enviados por alguns respondentes para completarem suas respostas geram em nós dúvida em relação à completude dessas respostas às perguntas sobre honestidade intelectual imbricada de forma implícita com a questão da proibição de uso. "Eu vou colocar que é ético para tudo pensando nisso. Que ele está traduzindo palavras isoladas. Tá bom? Ou expressões idiomáticas." - comentou P12 por mensagem de voz; verbalizando, assim, sua atitude e, possivelmente, a de outros questionados também, no momento de responder a essas perguntas. Com efeito, percebemos que a preocupação da P12 é com o tamanho do texto traduzido automaticamente, não interessando o tipo de tarefa ou se o uso acontece durante a aula ou em casa, como inferido anteriormente neste artigo e como a própria respondente expressa na mesma mensagem de voz por meio das seguintes palavras: "[...] qualquer atividade que seja, eu acredito que você pode usar um site de tradução automática ou Google tradutor desde que seja para expressões, para palavras isoladas, mas nunca para um tanto de texto."

Outra observação contida na já referida mensagem de voz da mesma respondente, que consideramos importante mencionar é a seguinte: "[...] para mim, uma coisa ou ela é ética ou ela não é ética". Então, a modalização presente nas opções de resposta propostas não se justifica para a respondente. Por não admitir meio termo, esse tipo de posicionamento poderia tornar menos difícil a normatização do uso da TA em planos de ensino de cursos ou ementas de disciplina quando se queira controlar a prática nessa perspectiva.

P11, por sua vez, condiciona "tudo" à ciência ou não do professor de que o aluno está usando TA como é possível ler no trecho seguinte:

Eu acho que a questão de ser ético ou não aluno usar um tradutor automático, tudo depende, né, se o professor sabe ou não que ele estava usando. [...] tanto faz usar dicionários online, tradutores para palavras, para expressões dentro da sala, em casa, desde que o professor saiba, desde que não seja escondido e desde que não seja com o intuito de enganar o professor [...] E enganar o próprio aluno, na verdade $[\ldots]$ (P11, mensagem de voz)

É importante salientar que a respondente considera que tudo depende se o professor sabe do uso ou não e se há o intuito de enganá-lo ou não, mas parece limitar o tamanho do texto a palavras e expressões. Além disso, P11 adverte que o aluno que engana ao professor, engana a si mesmo também. Ela encerra o seu comentário com as seguintes palavras:

[A] questão de responder simplesmente se é ético ou antiético é complicado porque existem muitas variáveis aí envolvidas, né, em relação a como o professor pediu que a tarefa fosse feita, né, se o aluno está, né, avisando o professor ou não que ele está usando, se o aluno está usando isso pro texto todo, se é só para palavras, né? Então tem muitas variáveis. (P11, mensagem de voz)

P7 faz a mesma observação sobre a dificuldade de julgar se tal prática é ética ou não, por mensagem escrita, nos seguintes termos: "Apesar de que essa pergunta e resposta me parece ser algo a ser discutido dentro de um contexto!".

Nesses trechos dos adendos dessas respondentes (P7, P11, P2), entendemos que elas exigem uma contextualização mais específica para que a questão seja discutida; ou seja, uma análise caso a caso.

Outro assunto contemplado, falando em atitudes, foi o diálogo entre professor e aluno sobre a TA. Então perguntamos aos participantes com que frequência eles discutem com seus alunos sobre uso de tradutores automáticos. À questão, 05 (cinco) responderam que o fazem com certa frequência, 04 (quatro) que o fazem apenas quando o assunto vem à tona e 3 disseram fazê-lo frequentemente. Então, foram convidados a dizer de que falam com seus alunos sobre a TA e todos (12) afirmaram que falam sobre possíveis impactos (positivos ou negativos) do uso da TA no seu processo de aprendizagem em relação à qualidade da mesma e à forma de usá-la (frequência de uso, finalidade de uso, etc.). Um quarto (03) deles asseverou falar também sobre o uso e a ética (se é fraude usar ou não, o que é fraude e o que não é). Como outras questões que discutem com os alunos, P2 e P11 disseram 
respectivamente discutir "[p] ossíveis enganos que a tradução automática não consegue identificar" e "a dependência e/ou falta de empenho em aprender". Da mesma maneira, P9 afirma o seguinte: "Mostro como conferir se a tradução automática foi eficiente, questiono o uso exagerado da tradução automática e discuto como seu uso pode ser mais adequado." Nesse ponto, podemos perceber uma ajuda do professor, ensinando estratégias de uso, embora haja uma preocupação com a frequência de uso.

Perguntamos também aos respondentes se o projeto pedagógico, plano de ensino ou a ementa de suas disciplinas falam sobre o uso da tradução automática por alunos ou professores. 11 (onze) participantes responderam negativamente e 01 (uma), a P6, respondeu afirmativamente. Quando the pedimos que informasse o trecho em questão, a respondente escreveu o seguinte: "Livro como escrever melhor em ingles cap. Usando traduções editora disal". Colocando a resposta dada pela participante P6 em perspectiva, consideramos a informação insuficiente para interpretarmos o destaque.

O último aspecto previsto para ser abordado neste artigo é o posicionamento dos respondentes em relação à integração da TA no ensino e na aprendizagem de línguas. Então, questionamos aos professores participantes sobre a utilidade da TA no ensino e na aprendizagem de línguas. Com efeito, esse é um recorte da grande discussão sobre a integração da tecnologia digital no ensino e na aprendizagem de língua. Vale especificar que apenas mencionamos o ensino junto com a aprendizagem por causa da relação entre os dois processos, da influência considerável dos professores nos alunos e da necessidade de se sintonizarem os dois processos no momento de refletirmos sobre a educação, embora um possa acontecer sem o outro. De fato, os recursos tecnológicos digitais já estão mediando a aprendizagem há muito tempo, com ou sem acompanhamento do ensino. A própria "Tradução Automática Didatizada" (TAD) pelos alunos, mesmo a malgrado dos professores (NOUATIN, 2018), é uma prova disso. Então, escolhemos abordar a questão sob esse ângulo, que é mais pertinente para nossa pesquisa. Portanto, perguntamos aos questionados, num primeiro momento, se consideram o tradutor automático uma ferramenta útil para o ensino e a aprendizagem de línguas, ao que 10 (dez) responderam afirmativamente, uma negativamente e outra respondente disse não ter opinião.

Em seguida, interessamo-nos pelo porquê de não considerar útil. Então, a única respondente que respondeu negativamente completou com o seguinte:

$\mathrm{Na}$ verdade, penso que, enquanto o tradutor funciona para palavras ou expressões isoladas como um dicionário, não vejo prejuízo em utilizá-lo. Porém, se utilizado para frases, parágrafos ou textos ele não permite que o aluno desenvolva suas próprias estratégias de aprendizagem, como fazer inferências ou identificar palavras-chave, por exemplo. (P12)

Percebemos que a respondente não considera, de fato, a ferramenta digital inútil para o ensino e a aprendizagem de línguas. Com efeito, na sua resposta, ela tornou a expressar a preocupação dela, compartilhada por outros professores, com o processo de aprendizagem do aluno, assumindo que pode vir a ser prejudicado se ele usa tradutores automáticos para traduzir unidades textuais maiores que "palavras ou expressões isoladas". Vale mencionar neste ponto os trabalhos de Clifford et. al. (2013) e de Nouatin (2018), que descobriram que os alunos usam principalmente tradutor automático justamente para isso, "como um dicionário" por acreditarem que o desempenho desse tipo de programa computacional é melhor traduzindo palavras e expressões isoladas, ao contrário do que afirma Henshaw (2020), que considera que é justamente quando "cai" a qualidade da tradução, uma vez que o algoritmo dos sistemas de TA funciona melhor quando conta com um cotexto. Falando em estratégias de aprendizagem, provavelmente já surgiram outras nessa nossa era digital e tudo leva a crer que agora existem estratégias de aprendizagem envolvendo a TA.

A seguir, procuramos saber quão útil os questionados consideram a TA para o ensino e a aprendizagem de línguas. Apesar de termos orientado, no questionário, quem não considerasse o tradutor automático útil para esse propósito a não responder à pergunta, P12 respondeu que considera o recurso um pouco útil, confirmando que não considera a TA inútil para o ensino e a aprendizagem de línguas como interpretamos no parágrafo anterior. Dos 11 (onze) respondentes que veem tal utilidade do recurso digital, incluindo a P12, 03 (três) o consideram um pouco útil, outros 03 (três) útil, outros 03 (três) muito útil, enquanto 02 (dois) afirmaram que é indispensável.

Também foi solicitado que os respondentes justificassem essa utilidade com exemplos, especificando, quando pertinente, que tipo de atividades envolvendo a ferramenta consideram conveniente desenvolver com aprendizes de línguas de acordo com seus níveis de proficiência (básico, intermediário ou avançado). Os exemplos dados foram o uso do tradutor automático pelo aluno para sanar dúvidas lexicais (palavras, expressões idiomáticas, gírias), descobrir 
sinônimos (P12), ampliar seu vocabulário (10 participantes) e o uso pelo professor com os alunos em atividades comparativas entre traduções automáticas e traduções humanas (às vezes tradução do próprio aluno como sugere P1) a fim de trabalhar questões de interlíngua e desenvolver consciência contrastiva entre as línguas envolvidas (P1, P3, P8), ou mesmo para demonstrar aos alunos que os tradutores automáticos podem ter falhas (P8) e assim leválos a usar a TA com senso crítico (P1). A respeito dos níveis de proficiência, apenas 4 participantes responderam, afirmando que a ferramenta pode ser útil em todos os níveis (P4 e P7), desde que seja bem utilizada (P2, P6), utilizada em casos pontuais (P7) ou "desde que se tenha claro o objetivo de cada tradução" (P3). Além disso, P7 acrescenta:

\footnotetext{
Mas ao mesmo tempo, procuro oferecer alternativas que possam motivar a autonomia dos alunos. Para alunos de nível de proficiência básico, sugiro o uso do Google Images sempre que houver dúvidas, de modo que eles possam associar palavras a conceitos e não traduções. Desse modo, tento instigar que apliquem estratégias como inferência, contextualização, desde o início do aprendizado. Para aqueles alunos que estão em níveis intermediários e avançados, sugiro o uso de dicionários de conceitos como alternativa à tradução. (P7)
}

Não há dúvida que quanto mais recursos e estratégias de aprendizagem o aluno tiver e dominar, melhor poderá desempenhar o seu papel no processo de aprendizagem, processo em que ele tem a maior responsabilidade. Por isso prezamos, entre outros fatores, a autonomia do aluno, conceito presente na resposta da P7. E como demonstram os resultados da pesquisa de Nouatin (2018), o uso da TA não compromete esse fator nem dificulta aos alunos o desenvolvimento de estratégias comunicativas ou de aprendizagem como inferência e contextualização, pelo menos de acordo com os dados gerados pelos participantes do estudo. Essas preocupações também estão presentes na justificativa da P12 para o fato de não considerar a TA útil para a aprendizagem de línguas.

\section{DISCUSSÃO}

Os professores participantes da pesquisa relatada neste artigo são todos usuários de tradutor automático. Todos usam apenas Google Tradutor tanto para fins pessoais quanto didáticos, exceto dois que afirmaram nunca ter integrado a TA às suas práticas docentes. Isso significa que nenhum deles rejeita a TA por aversão pelas Tecnologias Digitais da Informação e da Comunicação (TDIC).

Pesquisas (CLIFFORD et al., 2013; ALHAISONI; ALHAYSONY, 2017; SOMERS et al., 2006; MCCARTHY, 2004; GARCIA, 2010, NOUATIN, 2018) demonstram que aprendizes de línguas não maternas recorrem a tradutores automáticos para se comunicar e para aprender línguas. Dados da nossa pesquisa comprovam que os professores participantes estão cientes da prática ou imaginam que exista. Diante disso, os participantes da pesquisa manifestaram opiniões, percepções e atitudes que nos levaram a considerar que eles reagem na perspectiva das abordagens do "Não é confiável", do "Só palavras isoladas" e do "Se você não pode vencer seu inimigo, una-se a ele" de Henshaw (2020), podendo às vezes combinar duas ou as três abordagens.

Ainda em relação à finalidade de uso da TA por aprendizes de línguas não maternas, de acordo com Somers et al. (2006) e McCarthy (2004), alunos entregam aos seus professores traduções automáticas de textos primeiramente produzidos nas suas línguas maternas (ou outras) e de textos objetos de atividades de tradução, respectivamente, em lugar de produções escritas nas línguas que estudam e de traduções a serem feitas por eles mesmos como tarefa escolar. Isso é exatamente o que preocupa os professores participantes da pesquisa de Clifford et al. (2013). Essa preocupação foi verbalizada também por dois respondentes da nossa pesquisa. Inspirando-nos em Nouatin (2018) e em Alhaisoni e Alhaysony (2017), abordamos a questão da desonestidade intelectual em função do tamanho do texto traduzido e das circunstâncias de uso da TA (durante diversas tarefas na sala de aula ou em casa). Assim, chegamos à conclusão de que quanto maior o segmento textual, menos ético os professores participantes consideram que o aluno o traduza usando tradutor automático e de que o tipo de tarefa parece não fazer diferença, nem o fato de ser durante a aula ou em casa, inclusive ao fazer atividades de tradução. Ressaltamos que esses achados coincidem em todos os aspectos com os de Nouatin (2018): em linhas gerais, o que importa é o tamanho do texto traduzido automaticamente, o que significa dizer que não há problema enquanto o tradutor automático for utilizado como dicionário; a situação de uso da TA não tem muita importância.

Porém, uma participante da pesquisa que embasa este trabalho trouxe também outra variável que é a ciência ou não do professor de que o aluno está usando um tradutor automático. Para outra respondente, ou o uso é ético ou é antiético; não existe meio-termo. Outra opinião importante foi que são muitas variáveis envolvidas e que é 
preciso uma contextualização maior, uma especificação mais minuciosa das circunstâncias de uso para se determinar se há fraude (cheating, plagiarism) ou não. Alguns respondentes não concebem, por exemplo, a discussão da questão separando a opinião sobre 'fraude e tamanho do texto' da opinião sobre 'fraude e situação de uso'. Isso tudo limita o direito a se pronunciar e a responsabilidade de agir às professoras e aos professores, que são quem estão na sala de aula junto com os alunos e quem conhecem seus alunos e suas necessidades melhor que ninguém, embora as referências para as atitudes a serem tomadas em cada tipo de situação possam ser discutidas e estabelecidas junto com coordenadores de cursos, pedagogos, membros do comitê de ética, se houver na instituição etc.

A maioria dos nossos respondentes considera a TA útil, indispensável para alguns, no ensino e na aprendizagem de LE, para os alunos usarem para sanar dúvidas lexicais e ampliar seu vocabulário e para professores usarem para desenvolver nos aprendizes consciência contrastiva entre suas línguas maternas e as línguas que estão aprendendo. Com relação ao nível de proficiência, os dados indicam que, para os questionados, os tradutores automáticos são úteis em todos os níveis desde que bem utilizados. Então, não veem na TA uma ameaça, senão uma aliada, embora seja difícil dizer se isso é efeito da abordagem do "Se você não pode vencer seu inimigo, una-se a ele" (HENSHAW, 2020) ou não.

É digno de menção, neste ponto, o fato de a questão fazer parte de uma discussão maior sobre a integração das TDIC no ensino e na aprendizagem de línguas (NOUATIN, 2018), pelo menos no contexto geográfico em que realizamos a pesquisa relatada neste artigo. Dessa maneira, para encerrarmos esta discussão, salientamos que os tradutores automáticos, e as TDIC em geral, são aliados importantes na aplicação de abordagens de ensino e de aprendizagem de línguas baseadas nos princípios das metodologias ativas, que prezam a autonomia e a agência do aluno durante seu processo de aprendizagem.

\section{CONSIDERAÇÕES FINAIS}

A didatização da tradução automática por aprendizes de línguas não maternas é uma realidade notória como comprovam a pesquisa que deu ensejo a este artigo e diversas outras. Os professores participantes, não apenas sabem disso, como também usam o recurso digital tanto em suas práticas docentes (a maioria) quanto para fins pessoais (todos). Então, estão acostumados com a TA e têm atitudes positivas em relação ao seu uso por seus alunos, embora se preocupem com duas coisas como os professores de outros contextos: o risco de a TA comprometer a aprendizagem da língua e o possível uso fraudulento do recurso digital pelos alunos.

Com relação à última preocupação, embora o tamanho do texto esteja sempre presente nas respostas de quase todos os participantes como critério (uso indicado só para palavras e expressões, na opinião da maioria), para alguns participantes existem muitas outras varáveis envolvidas, como por exemplo, a maneira como o professor ou a professora pediu que a tarefa fosse feita ou se ele ou ela está sabendo ou não que o aluno está usando um tradutor automático, podendo até ser válida a tradução de textos completos dependendo do objetivo da atividade. Dessa forma, esses participantes sugerem que cada caso seja discutido dentro de seu contexto específico. A modulação adotada nas opções de resposta também foi questionada por uma participante, para quem ou o uso da TA é ético ou é antiético; para ela, não existe meio-termo.

No que diz respeito à integração da TA ao ensino e à aprendizagem de línguas, os participantes estão a favor, no geral, e veem utilidade para o recurso em todos os níveis de proficiência.

Dessa forma, acreditamos poder dizer que as percepções dos docentes participantes da pesquisa sobre a prática de uso da TA por aprendizes de línguas não maternas convergem com as dos participantes das pesquisas de outros contextos que abordaram esse aspecto do assunto e que foram citadas neste artigo, que eles têm adotado atitudes flexíveis diante da prática, que têm opiniões favoráveis em relação a ela e até mesmo à integração da TA ao ensino de línguas, desde que haja condições adequadas.

Ressaltamos que, além de contribuir para as discussões acadêmicas sobre o uso da TA no ensino e na aprendizagem de línguas não maternas no mundo, o trabalho se destaca pelo fato de ajudar a preencher a lacuna provocada pela insuficiência tanto de pesquisas realizadas no contexto brasileiro, como sinalizado por Nouatin (2018), quanto de trabalhos publicados em língua portuguesa.

Contudo, acreditamos que em uma abordagem holística de ensino de línguas não maternas na perspectiva de Rorschach, Tillyer e Verdi (1992), a TA pode ser associada de forma significativa e eficaz à produção de narrativas 
pessoais de estudantes de línguas não maternas. Mas, como os dados gerados neste estudo não tiveram esse foco e o espaço nesta publicação é limitado, esse tópico ficará para ser discutido em estudos futuros.

\section{REFERÊNCIAS}

ALHAISONI, Eid, ALHAYSONY, Maha. (2017). An Investigation of Saudi EFL University Students' Attitudes towards the Use of Google Translate. International Journal of English Language Education, v. 5, n. 1, p. 72-82.

ARRIBA GARCÍA, Clara de. (1996). Introducción a la traducción pedagógica. Lenguaje y Textos, n. 8, p. 269-283.

ASQUERINO EGOSCOZÁBAL, Laura. (2015). La traducción pedagógica en la enseñanza del español como lengua extranjera a estudiantes japoneses: propuesta de unidades didácticas para trabajar algunos aspectos problemáticos de la enseñanza del verbo. Dissertação de Mestrado em Tradução, Interpretação e Estudos Interculturais. Universitat Autònoma de Barcelona, Barcelona.

BRANCO, Sinara de Oliveira. (2009). Teorias da tradução e o ensino de língua estrangeira. Horizontes de Linguística Aplicada, v. 8, n. 2, p. 185-199.

CLIFFORD, Joan; MERSCHEL, Lisa; MUNNÉ, Joan. (2013). Surveying the landscape: What is the role of machine translation in language learning? @tic. revista d'innovació educativa,n.10, p. 108-121.

CONDE NOGUEROL, María Eugenia. (2018). Los traductores automáticos en línea como recurso metodológico en el aula de Español como lengua Extranjera. In: López-García, Camino; Manso, Jesús. (Eds.), Transforming education for a changing world. Eindhoven: Adaya Press, p. 304-312.

DUCAR, Cynthia; SCHOCKET, Deborah Houk. (2018). Machine translation and the L2 classroom: Pedagogical solutions for making peace with Google translate. Foreign Language Annals, v. 51, n. 4, p. 779-795.

GARCÍA, Ignacio. (2010). Can Machine Translation Help the Language Learner? ICT for Language Learning. Disponível em: http://conference.pixelonline.net/ICT4LL2010/common/download/Proceedings_pdf/T RAD02-Garcia.pdf Acesso em: 23 dez. 2020

HENSHAW, Florencia. (2020). Online translators in language classes: pedagogical and practical considerations. Disponível em: https://fltmag.com/online-translators-pedagogical-practical-considerations/ Acesso em: 09 jan. 2021.

KARNAL, Adriana Riess. (2015). As estratégias de leitura sem e com o uso do google tradutor. Tese de Doutorado em Linguística. Pontifícia Universidade Católica do Rio Grande do Sul, Porto Alegre.

LEE, Sangmin-Michelle. (2019). The impact of using machine translation on EFL students' writing. Computer Assisted Language Learning, v. 33, n.3, p. 157-175.

McCARTHY, Brian. (2004). Does online machine translation spell the end of take-home translation assignments? CALL-EJ Online. v. 6, n. 1, p. 26-39.

NIÑO, Ana. (2009). Machine translation in foreign language learning: Language learners' and tutors' perceptions of its advantages and disadvantages. ReCALL, v. 21, n. 2, p. 241-258.

NIÑO, Ana. (2020). Exploring the use of online machine translation for independent language learning. Research in Learning Technology, v. 28, p. 1-32.

NOUATIN, Gbènoukpo Gérard. (2018). O papel do tradutor automático livre na aprendizagem de línguas estrangeiras. Dissertação de Mestrado em Estudos de Linguagens. Centro Federal de Educação Tecnológica de Minas Gerais, Belo Horizonte.

PUTRI, Gustika Dayama; HAVID, Ardi. (2015). Types of Errors Found in Google Translation: A Model of MT Evaluation. Proceedings of ISELT FBS Universitas Negeri Padang, Padang, v. 3, p. 183-188. 
RORSCHACH, Elizabeth; TILLYER, Anthea; VERDI, Gail. (1992). Research on ESL composition instruction: the Fluency-first approach. In: TESOL 1992 Conference. Vancouver, B.C. Disponível em: https://files.eric.ed.gov/fulltext/ED350848.pdf . Acesso em: 09 jan. 2021

SÁNCHEZ IGLESIAS, Jorge Juan. (2009). La traducción en la enseñanza de lenguas extranjeras: una aproximación polémica. RedELE, 10. Disponível em: http://www.educacion.es/redele/Biblioteca2009/JJSanchezlglesias/Memoria.pdf Acesso em: 09 jan. 2021

SOMERS, Harold.; GASPARI, Federico.; NIÑO, Ana. (2006). Detecting inappropriate use of free online machine translation by language students - A special case of plagiarism detection. In: 11th Annual Conference of the European Association of Machine Translation. Proceedings of the 11th Annual conference of the European Association for Macbine Translation. Disponível em: https://www.aclweb.org/anthology/2006.eamt-1.6.pdf Acesso em: jan. 2018.

STAPLETON, Paul; KIN, Becky. Leung Ka. (2019). Assessing the accuracy and teachers' impressions of Google Translate: A study of primary L2 writers in Hong Kong. English for Specific Purposes, v. 56, p. 18-34.

Recebido: 2/2/2021

Aceito: 31/5/2021

Publicado: 22/7/2021 